\title{
Editorial
}

\section{INVESTIGACIÓN Y UNIVERSIDAD INCLUSIVA}

\author{
Saniel E. Lozano Alvarado
}

EDITOR ASOCIADO

Aunque en su formación básica e inmediata el concepto de educación inclusiva se relaciona con la opción de brindar oportunidades de educación a estudiantes con capacidades especiales (o limitadas), de manera que no queden fuera, marginados o excluidos, el concepto actual se relaciona con los procesos de mejoramiento, renovación y transformación progresiva del sistema, de manera que se ofrezca una educación de calidad a todas las personas sin distinción y adecuada a la realidad.

Según lo expuesto, la universidad inclusiva tiene el propósito de ofrecer una atención educativa orientada al óptimo desarrollo de los estudiantes, al mismo tiempo que promueve la cohesión e interrelación de los miembros de la respectiva comunidad: profesores, estudiantes, empleados administrativos y egresados.

Este tipo de universidad sólo es posible en el contexto democrático en todos los niveles, con claras opciones de acceso a una universidad abierta, de calidad accesible a todos. En ese ambiente, la universidad inclusiva se orienta a los objetivos de ayudar, apoyar, promover e impulsar el desarrollo interinstitucional, en un escenario amplio de solidaridad, de modo que se pueda intercambiar experiencias, difundir buenas prácticas, ejecutar e impulsar programas, proyectos y políticas educativas innovadoras, con la aspiración amplia de incorporar a los involucrados en la sociedad del conocimiento y del bien común.

De manera especifica, uno de los aspectos cruciales, estratégicos, primordiales, proclamados, pero no siempre logrados ni practicados en forma continua y distintiva, es la investigación, entendida no solo como actividad metodológica y sistemática, sino como opción real de descubrimiento, difusión y propagación del conocimiento científico y tecnológico, la creación cultural y la producción artística, cuyos resultados deben ampliar, iluminar y consolidar la actividad lectiva propia de las aulas convencionales. 
Precisamente, lo que pretendemos en estas páginas, como se puede apreciar a través de las sucesivas ediciones, es incluir en el contenido de IN CRESCENDO los trabajos de investigación de docentes, estudiantes y egresados, tanto de la ULADECH como de otras universidades peruanas y extranjeras. Los resultados no han tardado en manifestarse con diversas voces de reconocimiento y aliento. Por eso, desde un comienzo, estas páginas están permanentemente abiertas, no sólo para los miembros de la Universidad, sino para los autores de otra pertenencia y procedencia. En esa línea, abrigamos la confianza de una mayor participación en las tareas de la ciencia, la tecnología y la cultura en general, fines primordiales de toda universidad.

En este horizonte de la investigación como eje vital de la universidad inclusiva, nos satisface plenamente el liderazgo que viene ejerciendo la ULADECH en la Red de Universidades Inclusivas de Virtual Educa (RUIVE). Y es doblemente satisfactorio que dicho organismo sea conducido por el ingeniero Julio Domínguez Granda y por el P. Juan Rodríguez Ruiz, Rector de la corporación y Decano de la Facultad de Educación y Humanidades, en sus cargos de Presidente y Vicepresidente, respectivamente. Nuestras fraternas y sinceras congratulaciones para tan distinguidas autoridades universitarias. 